its powerful absorption, especially of the so-called chemical rays, is to limit the intensity of respiration, and to serve as a regulator of that process." He then proceeds further, and states that "the fact that only green parts of plants evolve oxygen, finds its sufficient explanation in the diminution of the amount of respiration, owing to the presence of the chlorophyll screen." Pringsheim thus regarded assimilation as a function of the protoplasm alone, with which the chlorophyll bas nothing to do, except in a purely negative way, by keeping off rays which would induce the opposite process of oxidation.

In the same year, Pringsheim announced his discovery of a body which he called Hypochlorin. This he was able to demonstrate in the chlorophyll corpuscles by the aid of certain reagents, notably dilute hydrochloric acid. $\mathrm{He}$ regarded hypochlorin as the first and most constant product of assimilation.

Both of Pringsheim's conclusions were sharply attacked, and an extensive controversial literature soon grew up. As regards the hypochlorin, it seems certain that Pringsheim was mistaken in the importance he attributed to this body. It has been clearly shown by Arthur Mayer, and others, that hypochlorin is not a product of assimilation, but is derived from the chlorophyll itself, hy the action of the reagents employed.

The other theory, that of the screen-action of chlorophyll, has not met with much favour from physiologists, and it is clear that this is, at any rate, not its only function. The investigations of Timiriazeff and Engelmann have proved that certain of the rays absorbed by the chlorophyll (principally those in the red) are just the rays most active in the decomposition of carbon dioxide. The chlorophyll, in fact, is not merely a screen, but is also a light-trap, which catches and detains those rays which are most effective in the assimilative work of the plasted. On the other hand, recent investigations as $t$, the action of light on protoplasm have shown that many pigments (such as those of spores and pollen-grains) are useful as screens, and have rendered it probable that this may be a function (though not the most important one) of chlorophyll also. The discovery, by Winogradsky, that certain Bacteria can assimilate carbon from inorganic carbonates, without chlorophyll, and in the absence of light, is a striking confirmation of the view that the seat of assimilation is the protoplasm itself, and to this extent Pringsheim's opinion is completely justified.

It would be unfair to deny considerable credit to Pringsheim for the boldness and originality of his physiological theories, and the energy with which he supported them. Yet it must be admitted that his views on these subjects were one-sided, and not characterised by the same sober judgment which distinguishes his morphological researches. Entering, in mature life, upon an unaccustomed field of investigation, he failed to add greatly to his previons reputation; and though much of his physiolngical work is suggestive, it has not given us, as he intended it should, a consistent theory of assimilation.

Passing over some of the physiological papers of secondary importance, we come to Pringsheim's last work (1888), which treats of the origin of calcareous incrustations on water-plants. $\mathrm{He}$ explains this process by the removal of carbon dioxide from calcium bicarbonate during assimilation, causing the precipitation of the insoluble calcium carbonate. This theory is supported by the interesting observation that the incrustation only takes place in the light; but it miay be doubted whether the explanation given is sufficient.

We have not attempted to record all Pringsheim's researches, but enough has perhaps been said to give some idea of his life's work.

In addition to his original investigations, Pringsheim rendered a great service to science by means of his magnificent Year-book for Scientific Botany, which shares, with the botanical portion of the French Annales dcs Sciences Naturelles, the honour of constitu'ing the finest serial record of morphological and physiological botany. It is satisfactory to hear that, since the death of the founder, the editorship of this great publication has been undertaken by two such distinguished botanists as Profs. Strasburger and Pfeffer.

By the death of Pringsheim we have lost another of the leaders who guided scientific botany through the period of its most vigorous growth. Very few of his generation now remain they have left worthy successors behind them, but the work of Pringsheim, in the field of morphology, will not soon be rivalled.

NO. 132 I, VoL. 51$]$
D. H. ScotT.

\section{THE ANTITOXIC SERUM TREATMENT OF} DIPHTHERIA. ${ }^{1}$

THE subject with which we shall deal to-night, though at first sight of interest to the physician only, has heen so fully discussed in the public prints, and has been so bitterly and irrationally opposed on the one hand (perhaps also unreason. ally heplauded on the nther), that hose who take even a general interest in the public health, or who are wish/ul to obtain some insight into the pracical and scientific aspects of a new system of treatment, may well be interested to know something of what is being so freely discussed in the columns of our daily newspapers. Beyond this, however, many take a more personal interest in a method of treatment which holds out promise of help in the cure or amelioration of the symptoms and conditions met with in diphtheria, a disease which, very justly, is looked upon as one of the most dangerous with which the physician has to deal. To begin with, I should like to make a frank confession. With that con-ervatism $x$ hich is met with even in the most radical of natures, many, of whom I was one, felt disposed to treat antitoxic serum as belonging to the same group of substances as tuberculin, around which u as constıucted a theory of which the laboratory experimental basis, though ap. parently fair and firm, was as yet insufficient for the support of the structure of therapeutic treatment that $w$ as aiterwards raised upon it. I followed the earlier experiments on this new method with great attention; I carefully analysed the principles on which the method was founded, and then with some mis givings watched the gradual development of the treatment as applied to ac ual cases of diphtheria. I was inclined to receive the statistics with great reserve, as I felt that this new method, like all new methods of treatment, might be making cures in the minds of the observer, and not on the bociles of the patients. Now, however, I am convinced that whatever justificalion my incredulity may have had from the con-ideration of previous experiments, none could be claimed in connection with the experiments that were carried out in the inves igation of this special subject, and I am thoroughly satisfied that, alihough the antitoxic serum treatment may not come up to the expectations of all the rash wilters on the su ject-for many people seem to think that it should be a specific against diphtheria in all its stages-it promises, and this promise has in pait been reteemed, to diminish the diphtheria case mortality in a very remarkable manner.

\section{What is Diphtheria?}

It is primarily an inflammation of the mucous membrane (the moist skin) of the tonsils, of the soft palate, of the upper part of the gullet, and of the upper part of the windpipe. During the course of this inflammation, which appears to be set up by the aciion of a special bacillus, there are usually thrown out some of the fluid elements of the blood and some of he white cells that float in the blood; these coagnlate and form a soft toughish layer or filı which offers an excellent food and resting place for this bacillus, which under such favourable conditions secretes or manufactures a most virulent poison. This poison is rapidly absorbed into the blood and is carried to various parts of the body; its effects are evident at first only on the nervous system, but afterwards on the muscles.

\section{The Bacilius of Diphtheria.}

First as to the bacillus. In 1875 Klebs described a short bacillus which he found on the surtace of the greyish leatherlike diphtheriic false membrane or film. Follouing up these observations, Loeffler traced a definite etiological relation. ship between this bacillus and diphiheria. First he obtained pure cultures of the bacillus by growing it on solidified blood serum, or on a mixture of three parts of blood serum and one part of neutralised beef bouillon con aining exiract of beef, I per cent. of peptone, o 5 per cent. of coumon salt, and I per cent. of grape sugar. This organism may be readily detached from the surface of the false membrane by pressing firmly but gently with a little bit of cotton wadding twisted round the end of an iron wire or an ordinary penholder. When stained and examined under the mi roscope the diphtheria bacilli are found to be small rods fom 3 to $6 \mu$ (I $\mu$ $=\frac{1}{30} \cdot h$ of an inch) in length, fairly plun p, straight, or slightly curved, :on etimes wedge-shaped or poin ed, but usually somewhat enlarged and rounded at the ends, where also in stained

1 A lecture delivered at the Royal Institution, on Friday, February 8, by Dr. G. Sims Woodhead. 
specimens the protoplasm is more deeply tinted than in the centre. This organism grows singly or in groups, or felted 10gether to form a net-work; it may nccur in irregular masses of considerable size. When these hacilli have been growing for some time on an artificial nutrient medium, they appear to be seginented, the stained material accumulating in small round nodules placed at intervals $u$ ithin a kind of membrane which is only very deli. cately tinted. During the past five weeks I have examined about 600 specimens taken from the throats of diphtheria patients, and I may say that in nearly every case where the tisease has been diagnosed hy the physician in charge, as being one of diph. theria, these typical bacilli have been found, whilst in those cases in which there was any doubt as to the nature of the disease, similar bacilli were found in some, but not in others.

This is of importance, hecause we shall find that this bacillus gives us the substance with which animals are rendered immune to the attacks of the bacillus itself, these immune animals in turn supplying the antitoxic serum. To prove that this bacillus is really the cause of the disease, Loeffler, in an elaborate series of experiments, inoculated the pure cultures of the bacillus grown on artificially prepared media, into animals; he was thus able to set up characteristic lesions, especially if he took the preliminary precaution to abrade slighily the mucous membrane, thus as it were ploughing the ground before scattering the seed. On such abraded surfaces the bacilli grew very luxuriantly, and false membranes were produced ; in these lesions the bacilli could afterwards be found and again separated in pure cultures, whilst the characteristic toxic symptoms of diphtheria were in each case experimented upon, repeated with the utmost fidelity. Loeffler also pointed out a mo:t important fact in connection with the presence of the organism in the body. He found that it was strictly confined to the local wounds or lesions in the throat and posterior part of the nose, and he was also able to prove that in this position these organisms commenced to manufacture most virulent poisons, which, unlike the bacill, can become diffused throughout the body. Klein and Sydney Martin in this country have both made very valuable contributions to our knowledge, the former concerning the bacteriology of the disease, the latter in regard to the chemical action on the tissues of the toxic or poisonous products of the bacillus.

\section{The Toxines of Diphtheria.}

Martin found that after the poison formed in the throat has made its way into the internal organs of the body it undergoes certain changes; it is broken down into somewhat less poisonous compounds, but these, accumulating at certain points, act especially on the nerves and muscles. It appears then that we have to deal with two sets of poisons : a very virulent poison formed by the bacilli directly from the fibrin and albuminoids of the fluids of the blood, exuded on the surface of the mucous membrane; and secondly, a less poisonous series which appear to accumulate especially in the spleen. So long as these poisons remain in the body we have the general fever, rise of temperature, and altered conditions of circulation (as evidenced by the pulse), so characteristic of the disease. At a later stage, sometimes afier all the primary symptoms of diphtheria have passed away, there are of $t \in \mathrm{n}$ met with what are called post-diphtheritic paralyses, which are due apparently to alterations in the nerves going to muscles, especially those going to the delicate muscles of the soft palate and around the opening into the windpipe, though other groups of nerves and muscles may be similarly affected. These post-diphtheritic paralyses may be due then to the action either of the virulent poison (ferment) formed in the membrane, or of the somewhat less puisonous but more stable toxines that are formed in the later stages of the disease. Through the kindness of Dr. Martin I am enabled to show you figures of nerves and muscles, the degeneration of which is due to the action of these poisonous substances. It is here unnecessary to enter into any detail as to the minute changes that take place in the nerve and muscle fibres, but on comparison of the affected nerve fibres with a healthy nerve fibre, it is evident that we have here grave structural alterations which must interfere most materially with the power of the nerve to conduct nerve impressions from the spinal cord to the muscle. The outer part or sheath of the nerve is in some places entirely wanting, whilst in other cases the axis cylinder or core of the nerve is either greatly attenuated or entirely absent. The prison in these cases has set up changes by which the communicating parhs between the muscles and the spinal cord and biain have become thoroughly disorganised. The muscles, too, instead of being formed of cleanly striated fibres, have this striation greatly obscured, first by a kind of cloudy or ground-glass look, and later by the appearance of a number of strongly refractile granules. These, when stained with osmic acid, become black, from which we argue that they are composed of fat, and it is said that the muscle has undergone a fatty degeneration, the muscular protoplasm being partially converted into fat; ultimately the striation may be almost lost. In a case of diphtheria, then, the following stages may be traced: a sore throat (often simple enough to begin with), by which the mucous membrane is prepared for the recepti'n of the diphtheria bacillus. The diphtheria bacillus hecomes implanted on this surface, gives rise to an acute inflammatory condition, and, subsisting on the inflammatory exudation, sets up a local manufactory of a most virulent poison. This poison, absorbed into the circulation, at once acts on the nervous system, although a certain proporion seems to be broken down into more stable, but less virulent, poison, which remains in the body, and may continue to act for a considerable time on the nerves and muscles.

\section{Immunity against Diphtheria.}

Whilst these poisons are attacking the more highly organised, and therefore less stable tissues, they are stirring up or stimulating the other tissues of the body to resist their invasion and action. If tris were not the case, any one attacked by diphtheria must eventually succumb to the disease; but we know a considerable proportion of the cases of diphtheria recover even when no treatment at all is resorted to. Whatever may be the exact explanation of this recovery, we know that it depends upon the power of certain cells in the body to accommodate them-elves to the presence of the toxines, and to go on doing their work of scavengering and of removing foreign substances from the body even under what originally were adverse conditions; during this process the cells become so profoundly and permanently altered that the patient is for some time protected against further attacks of the same disease. It was originally maintained that this alte). ation was entirely confined to the cells, but it is now generally accepted that these cells form or secrete substances which, thrown into the blood, either act directly upon the toxines so as to interfere with their activity, or so react upon the cells that they are able to continue their work in the presence of the toxine. At all events, a certain immunity against the disease is acquired. Upon these various theories is based the rationale of the antitoxic serum treatment of diphtheria. Ferran claims to have been the first to obtain such a condition of immunity against diphtheria in animals; shortly afterwards, Fraenkel in Germany obtained similar results. Seeing that this immunity depends upon an alteration in the composition of the serum, should it not be possible, argued Prof. Behring, to take the serum of an immunised anımal and tiansfer it to a patient suffering from diphtheria, so as to help the tissues and cells of the patient to cope with the toxic products of the diphtheria bacillus during the earlier stages of the disease, inducing, as it were, a kind of artificial immunity to heip the patient over the acute period of the attack when the poisons, though most virulent, are most unstable, and when the tissues have not yet become acclimatised to the presence of the toxic products of the bacillus; when, in fact, they are paraly-ed anc are able to do litıle to protert themselves. Behring so followed up this idea, that he was able to initiate a system of treatment which promises to revolutionise our therapeutic methods in the treatment of certain specific infective diseases.

\section{The Production of Antitoxic Serum.}

Working on the fact that an animal might be rendered more and more insusceptible to the action of the loxic products of bacteria, Behring found that he migh: proceed in either of two ways. He might make an artificial wound with a nee IIe, and introduce weakened bacilli into the animal, the weakened bacilli then growing but feebly and producing a modified toxine. After the effects of the first dose had passed off, he was enabled to increase the dose and to use more active bacilli, injecting them first into the tissues and eventually directly into the circulation, with the result that enormous doses of virulent diphtheria bacilli might ultimately be introduced without giving rise to more local swelling or general febrile disturbance than was first noticed when the small dose of modified bacilli was introduced. Such a method as this, however, was attended with considerable drawbacks, as it was almost impossible to gauge, at NO. I $32 \mathrm{I}$, vOL. $5 \mathrm{I}]$ 
all accurately, the number and strength of the bacilli. Not so, however, with the products of the micro-organisms, the activity of which could of course be more accurately measured, and the dose more accurately graduated. The bacilli might multiply and continue their action on the tissues, but the poisons when injected alone would not alter in quantity or activity. As may be readily imagined, the fluid constituents of the blood can only contain those substances that are introduced into it from without, either through the vital activity of the cells of the body, the products of which must be thrown into this fluid before they can be excreted, or through artificial injection. The antitoxic substances then found in the blood of an immunised animal, must in the case of natural immunity following an attack of diphtheria be the result of the activity of the tissue cells, especially of the connective tissue and white blood cell groups which have been "stimulated" by the toxines introduced from without, from the false membrance in the throat. Where it is desired to produce an artificial immunity, and an "artificial" antitoxic serum, the cells are stimulated by the introduction into the body of artificially prepared toxine. The cells acted upon by the toxine elaborate the protective fluid, which is thrown into and accumulates in the blood. This substance may act in one of several, or even in several ways. (I) It may directly antagonise the diphtheria toxine, and may thus prevent the paralysing action of these poisons on the scavengering cells or phagocytes, as they are called ; these, left free to perform their proper functions, can deal with the foreign elements that have got into the blood, and also with the bacilli at the seat of the local attack, for, as has been pointed out by several foreign observers, and by Ruffer in this country, immediately beneath the layer of bacilli in the false membrane there is usually a very considerable accumulation of leucocytes, especially in those cases in which recovery ultimately takes place. (2) The antitoxic substances may act on the bacilli, inhibiting their growth and interfering with their power of producing toxines. This of course can only be a local action should it play any part in the process. (3) These substances may act directly on the cells of the blood lymph and tissues, so stimulating and strengthening them that they are able to perform those functions above mentioned. It is at present difficult to state which of these processes is the one, or the most important, in protecting or curing the patient, and it may be that all play a part. It may be that the tissue cells, when acled upon by the specific diphtheria poison, become so modified that they are enabled to produce or secrete a substance which directly antagonises the action of that poison. This substance, thrown into the blood. remains there for some time, rapidly accumulates as larger and larger doses of the poison are thrown in, neutralising the poison, whose power of doing damage to the tissues is thus held in check, but remaining for some time after the toxine has disappeared; or this antitoxic substance, reacting upon the cells, may render them less susceptible to the action of the toxine.

The earlier immunising experiments were naturally performed upon the smaller animals, such as rabbits. Then Behring used sheep, and after various other animals had been tried, the horse was selected by Roux and Nocard as perhaps the best of al animals from which to obtain antitoxic serum. In the first place, he is comparatively insusceptible to the action of the diphtheria bacillus-even considerable doses of living bacilli may be injected under the skin without producing anything more than a slight local swelling and a rise of temperature. It has also been found that horse serum, when injected, produces little or no change in the healtby human subject-that is, the serum seems to mix perfectly well with human blood plasma, and there is comparatively little danger of the extra serum being excreted by the kidneys in the form of albumen. This is a most important point, and one that no doubt influenced Roux and Nocard in their selection of the horse as an animal from which to obtain immunised serum. Beyond this, however, the blood, when drawn from the vessels, separates very perfectly into two portions-a firm clot, which if the blood be caught in a cylindrical glass jar, forms a kind of column in the centre, and a clear straw-coloured serum which accumulates around the clot, and forms a layer often several inches deep above it. This serum contains the antitoxic substances. Lastly, considerable quantities of blood can be obtained from such a large animal as the horse, and if he be well fed, groomed and exercised, the process of bleeding may be repeated pretty frequently without causing any inconvenience to the animal ; in fact, as one observer said, he stands bleeding as well as did our forefathers, who thought as little of being bled as we think of going to Aix or Buxton.

Let us now turn for a moment to the method of treating the horses that we wish to render immune, in order that they may supply the antitoxic serum that is to be used for the treatmen of cases of diphtheria. Roux's method, which is that that has been most carefully described, and which is the one used in this country first by Dr. Ruffer at the British Institute of Preventive Medicine, and then by Prof. McFadyean at the Royal Veterinary College, consists in introducing diphtheria toxine of a given strength in gradually increasing doses, until the blood of the animal so infected is found to contain a sufficient quantity of the antituxine.

\section{Preparation of Diphtheria Toxine.}

The toxine with which the animal is to be injected is prepared as follows :-A broth is prepared by soaking a pound of finelyminced beef in water. This is allowed to stand for twenty-four hours in the cold. To the fluid expressed from the meat fibre at the end of that time is added $\frac{1}{3}$ per cent. of common salt and 2 per cent. of peptone (meat artificially digested by pepsine). This broth is then rendered faintly alkaline by the addition of soda salts or caustic soda. This is done because it is found that the diphtheria bacillus cannot grow at all vigorously, or form its poisons rapidly in an acid solution, and such poison as is formed is neutralised, or is unable to act in the presence of even a faint trace of acid. It is found that even in Roux's solution, which is always faintly alkaline to begin with, an acid reaction soon appears, but, after about ten days, this is replaced by an alkaline reaction, and as soon as this takes place, the growth of the bacilli takes on new activity, the quantity of toxine is increased, and it becomes much more virulent. Roux found that he obtained his most virulent toxines after a month's growth. If the growth is allowed to go on longer than this, a process of oxidation appears to take place, and I have found that the toxine from a culture carried on for two months had already lost much of its toxic activity. It should be noted that a virulent bacillus should always be taken in the first instance, otherwise the results may be very disappointing.

This nutrient material is placed in a layer of not more than half an inch thick in a flat-bottomed flask, which is plugged with cotton wadding, and then closed with an indiarubber cork or cap. Through this composite plug three tubes are passed into the flask; the two lateral tubes are bent at right angles, both inside and outside the flask; whilst the centre tube is fitted with a small thistle-head, which may be plugged with cotton wadding, and then closed with an indiarubber cap. The outlets of the lateral tubes are also plugged with cotton wadding, and the whole apparatus is kept for an hour or two in steam maintained at a temperature of $100^{\circ}$ C. (Flasks so treated may be preserved for years without any change, beyond some slight evaporation, taking place in the broth.) A small quantity of a pure broth culture of the virulent diphtheria bacillus is now drawn into a long thin pipette, the indiarubber cap and the cotton wadding plug are removed from the thistle-head, and the contents of the pipette are introduced; the pipelte is withdrawn, the cotton wadding is replaced, the indiarubber cap is fitted in position, and the flask is placed in an incubator which is maintained at the temperature of the body $\left(984^{\circ} \mathrm{F}\right.$., or $38^{\circ} \cdot 2^{\circ} \mathrm{C}$.). As soon as the growth is well started (usually at the end of about twenty-four hours), a current of moist air is made to pass continuously over the surface of this cultivating fluid, the air being first warmed and saturated with moisture, in order as far as possible to prevent evaporation. A fine flocculent deposit soon makes its appearance on the bottom of the vessel, the supernatant fluid remaining clear. This deposit increases in thickness, much more luxuriant growth going on aiter the first ten days. Toxine is formed by the diphtheria bacilli so long as they can grow freely - that is, so long as they can obtain suffcient nutrient material from the fluid and from the air that is continually passing over the surface. At the end of a month, if all these precautions are taken, the toxine should be of such a strength that $\mathrm{I} / \mathrm{loth}$ of a c.c. (about two or three drops) injected into a guinea-pig weighing 500 grammes (over 17 ounces) will kill it within forty-eight hours. The strength of the toxine or poison may be a little greater or a little less than this, but it is a comparatively easy matter to measure the strength, and therefore to graduate the dose to be used in immunising the horse. This only holds good, however, if the active diphtheria bacilli

NO. I 32 I, vOL. 51$]$ 
are removed or destroyed ; these, if left in the Huid, would be a complicating and inconstant factor in the equation. In order to kill these bacilli the Germans recommend the addition of $\frac{1}{2}$ per cent. of carbolic acid to the culture; the dead bacilli falling to the bottom, leave a perfectly clear supernatant fluid. The French, on the other hand, recommend the sepa:ation of the bacilli from the fluid by means of a PasteurChamberland filter. By this means a clear virulent poison which does not contain any diphtheria bacilli is obtained. With this fluid a horse with a good constitution, and which has been proved to be free from tubercle and glanders, is injected under the skin of the side of the neck in front of the shoulder. Small doses are first injected, either pure or with the addition of $1 / 3$ of the volume of weak solution of iodine of potassium. It the fluid is of full strength, only about $\mathbf{2}$ c.c. can be given at the first injection. This is followed within twenty-four hours by a local swelling at the seat of injection, about the size of the palin of the hand, and the temperat ure may rise $\mathrm{I}^{\circ}$ or $2^{\circ} \mathrm{F}$. $\left(1^{\circ}\right.$ to $\mathrm{I}^{\circ} \mathrm{C}$.), otherwise the general health of the horse does not seem to suffer. He eats well, and unless regularly exercised may become very lively; of this we have had ample evidence during the recent frost and snow, when it has been unsafe to give much exercise to horses that are not very sound in limb, ald as a result they have been very fresh indeed. As soon as the swelling has disappeared and the temperature has receded to the original level, a somewhat larger dose is given; the same process is repeated time after time (the dose being gradually increased to bring about the same amount of swelling and ise of temperature) for about three months, or until such time as the requisite amount of immunity is acquired, i.e. until the antitoxic action of the blood is sufficiently marked. That there is a gradually increasing immunity is evidenced by the fact that enormousıy large doses of the toxine in the later stages of the treatment produce even less local and constitutional disturbance than was ohserved after the first few injections of comparatively small quantities.

The blood is now drawn off from the jugular vein of the immunised horse by means of a metal cannula or tube to which is attached an indiarubber tube; these are first thoroughly boiled, in order that noliving micro-organisms of any kind may remain on or in them, and the skin of the horse is carefully cleansed with antiseptic lotions. The indiarubber tube leads the blood into a flask or vessel which has also been carefully sterilised, and provided with a well-fitting cotton-wadding plug or glass-stopper. The vessel when filled is placed in an icesafe until the solid part, the clot, is completely separated from the fluid-the serum. From each gallon of blood about one quart of serum is expressed, thuugh this varies considerably in different cases, and according to the time that the separation is allowed to continue (24 to 48 hours). This serum, a limpid straw-coloured fluid, is carefully decanted under strict antiseptic precautions, and, mixed with carbolic acid or camphor, is stored in small phials, each of which contains about a sufficient quantity for the treatment of a single patient. In the Pasteur Institute, and in the British Institute of Preventive Medicine, the antitoxic serum is apparently brought up to such a strength that $\frac{1}{1 \cup 0}$ of a c.c. injected into a medium-sized guinea-pig (500 grammes, or over 17 ounces) will protect it against an injection twenty-four hours later of $\frac{1}{3}$ c.c. ot a culture of living diphtheria bacilli strong enough, if given by itself, to kill the guinea-pig in twenty-four hours. It is usually recomrnended that 20 c.c. of this serum should be given at the first dose, and that if necessary a second ro c.c. should be given half an hour later. The method of testing the strength of the serum adopted by the Germans is that devised by Ehrlich, who takes ten times the lethal dose of diphtheria toxine, and in a test-tube adds a definite and known quantity of the blood to be tested. This mixture is then injected into a guinea-pig, and if the antitoxic power of the blood has been gauged aright, the animal does not suffer in the slightest degree from what under ordinary circumstances would lisil ten guinea-pigs. The addition of less or weaker serum, or of more toxine would leave the mixture still toxic.

In order to obtain a definite standard with which to compare the antitoxic power of any serum, and to determine the dose of such serum, Behring and Ehrlich have described what they term a normal antitoxic serum-that is, a serum of such a strength that $\frac{1}{1}$ th of a c.c. added to ten times the lethal dose of diphtheria toxine is exactly sufficient to render it innocuous. I c.c. of such normal serum contains one "immunisation unit," and should be sufficient, when added to a hundred times the lethal dose and injected, to render it innocuous. In horses wholly immunised the serum may be fifty or even a hundred times as active as the normal serum above mentioned and the dose to be given varies according to the number of immunisation units in any sample. It is not here necessary to go into the question of dose, but it may be stated that 500 of these immunisation units are usually necessary to produce the desired effects in cases of diphtheria, though in some cases still larger quantities have to be used. Behring now supplies four strengths of the serum, the weakest (marked with a yellow label) is sent out for injection of cases where the disease has not alreacly been contracted. The next (marked with a green label) is of a strength of 600 antitoxine units, and is given to those cases in which the treatment is commenced at the very outset of the disease - that is, when the first symptoms of diphtheria manifest themselves. The next stronger antitoxic serum (white label) equals 1000 antitoxine units, and is used for cases somewhat more advanced in which the prognosis is at all grave; whilst in still graver cases, and where the symptoms have been developed for some considerable time, it is often necessary to give a serum of 1500 units; this is marked with a red label, and is of course highly concentrated in order that the size of the dose may not be unduly increased. In place of No. I, healthy children ance adults who are exposed to diphtheritic infection may receive a quarter of the dose of the green label flask, which Behring considers will protect against diphtheria with very great certainty. Although these general directions are laid down, it is strongly insisted upon by Behring, Kossel, Roux, and in fact by all those who have had experience of antitoxic serum, that the dose must vary according to the severity of the disease, so that much must be left to the discretion of the medical practitioner in charge of the patient. The great error into which those who first use this agent fall, is the administration of far too small a dose, especially in the case of children, for whom the dose is nearly as large as it is for adults. For this reason some of the statistics published in this country and abroad are far too unfavourable to the method. The great drawback with this method is that the dose necessary to be injected is so large but in the loose tissue of the side of the chest, the back, or the buttock, immediately under the skin, the fluid soon disappears. It is hoped that before long, however, the active principle may be separated, and so obtained in smaller bulk.

So far we have dealt principally with the antitoxic serum as prepared by Behring and Roux and by Roux's method, which is certainly attended with comparatively few difficulties; these, however, have the disadvantage that they take from three to six months to give the desired results. In order to do away with this disadvantage, Klein has carried out a series of experiments in which he has been able to ot tain serum of considerable activity in as short a period as twenty-three days. Instead of introducing the poison only, he adopts the plan used by Behring and Roux in their earlier experiments, of injecting living bacilli which have lost a certain degree of their activity, using for this purpose old cultures. $\mathrm{He}$ afterwards introduces toxine along with more virulent bacilli, and thus obtains in the animal such a degree of immunity that it is enabled to withstand or to react very slightly to more than a fatal dose of diphtheria bacilli. By the third week the animal will bear the injection of large quantities of virulent bacilli, and by the end of twenty-three or twenty-six days the serum has acquired such antitoxic properties that $I$ c.c. of it will protect 40 to 80 guinea-pigs against a lethal dose of living diphtheria bacilli. It is difficult to compare these results with Roux's and Behring's, but Klein's serum has been used with marked success in certain cases of diph. theria. It appears to have a special power of causing the membrane to clear away, and so to remove the manufactory of the poison, as on this membrane the diphtheria bacilli accumulate. This method is mentioned as one that may be used especially where it is desired to obtain antitoxic serum quickly.

Smyrnow has suggested quite a different method of preparing antitoxine. Under Nencki's advice he passed electric currents through the serum of animals, and was thus able to endow it with a certain immunising power. But he was still more successful in obtaining powerful antitoxine by electrolysing diphtheria bouillon cult ures; curionsly enough, the more virulent the culture the more powerlul was the antitoxic substance he obtained. When this antitoxic substance was injected into a ral,bit, which twenty-four hours before had received about $\frac{1}{2}$ c.c. of a two or thre e days old diphtheria bouillon culture, there 
was a rapid rise of temperature followed by marked improvement in the condition of the animal. This observer believes that antitoxine can he obtained by this method that will be much more suitable for the treatment of the hum sn subject than tho ie obtained by the ordinary methods. His experiments, however, are far too few to carry any great weight, though they open up a most interesting field for future investigation.

(To be continued.)

\section{UNIVERSITY AND EDUCATIONAL INTELLIGENCE.}

CAMBRIDGE.-The extension of the buildings of the Cavendish Lahoratory is about to be undertaken, at an expense of over $£ 4000$. About half the cost will be met from the accumulated fees of students working in the lahoratory.

Mr. E. Hamilton Acton, Fellow and Lecturer in Chemistry of St. John's College, died suddenly, from heart disease, on Friday night. Mr. Acton was only in his thirty-third year; but he had earned a considerable reputation as a chemist, and his researches in vegetable chemistry, in particular, were of importance He was an able and successful teacher. His funeral on Tuesday was attended by some hundreds of the junior memhers if the University, and by representatives of all the scientific departments.

Mr. Robert Perkins, of Jesus College, Oxford, leaves England next week for Honolulu to resume his investigations on behalf of the Joint Committee appointed by the Royal Sociely and the Bri ish Association for the zoological exploration of the Sandwich Islands. The large collections he mare there during his former stay (March I892 to September 1894) have heen suhmitted to various specialists, with results that show him to be an indefativable ohserver in all branches of terrestrial zoology ; and, since his return to England last autumni, he has been busily engag $\mathrm{d}$ in discovering what has yet to be done to complete our knowledge of the indigenous Fauna which is so rapidly disappearing.

THE County Councils of Northumberland and Durham are truly advancing technical education by affording asistance to Dr. W. Somerville, Professor of Agriculture in the Durham College of Science, to carry out extensive manurial trials. The experiments were begun in 1892 , on nine farms in Northumberland; in 1893, when Durham joined in the work, the number of fa'ms rose to twenty-six ; while during 1894 , the trials were made at no less than forty-three different centres in the two counties. The investigati ins must have a not inconsiderable influence upon the prosperity of the agriculture of the district to which they refer.

THE Technical Instruction Committee of the Essex County Council, wi h a view to promoting the spread of scientific knowledge among those engaged on the coast in the tishing ind's' ries, started a mode-t hiological station at Brightlıngsea last year, and, under the superintendence of $\mathrm{Mr}$. J. T. Cunningham, a number of spec'mens were cullected for the purposes of demonstration. Some experiments on the continental method of growing oysiers were also commenced hut, owing to the unfaviourable character of the season, the results could not be carried very far. We are glad to learn, however, that the Committee, in conjunction wi'h the Borough Cunncil o' Colchester, propose to cary on the work of the station, and that the Fishmongers' Company hive also shown their appreciation of the movement by giving a grant of $£ 50$ per annum for three years.

THE Manchester Town Council have accepted a tender for the erection of a technical schuol at a cost of $£ 140,000$.

\section{SCIENTIFIC SERIALS.}

American Fournal of Mathematics, vol, xvii. No. i. (January, 1895). - Sur une Iransformation de mouvements, P. Apuell, is a treatment of Ellıot's problem (Comptes rendus, 1873 ), and of a question solved by Mestschersky, in the Bulletin des Sciences Math. 1894, as a particular case of transformation if movements.-An extract from a letter addressed to I)r. Craig hy M. Hermite, gives the result of an invest'gati in of the asymptotic value of $\log \Gamma(a)$ when $a$ is $\operatorname{large}$. - On the first and second logaithmic derivatives of hyperelliptic function; by Oskar Bolza, opens with a statement of certain well-known theorems of the theory of elliptic functions, and then extends these and some a'lied theorems to hypereluptic functions.-Sur la definition de la limise d'une fonction. Exercice de logique malhématique, by Prof. Peano. The definution is one previously used $1 \mathrm{y}$ the writer, and also by two or three previous writers. It is practica!ly given by Abel (Works ii. p. 199), in the form. "Pour qu'une 'érie $\Sigma u_{\mathrm{n}}$ soit convergente. il faut que la plus petite des limites de $n u_{\mathrm{n}}$ soit zéro." The same ger eral idea of a limit is given in Cauchy's "Cours d'Analyse algébrique" (182r, p. r3), "quelquefois .... une expre-sion converge à-la-fo s ver- pluvieurs limites différentes les unes des autres." Priff. Peano works on this refinition, and demon-trates at come length its principal properties. To this end he emplovs la log que mathématique, "Cette science s'est rapirtement déve'oppée de nos jours, et on l'a appliquée dans plu-ieurs travaux."-Dr. E. McClıntock contributes an article on thecre us in the calculus of enlargement (a paper read before the American Mathematical Society, August 14, 1894). It is an in'eresting sequel to his essay on the calculus of enlargement (vol. ii. pp. IOI-I6r). - In his note on Foucault's pentulum, Mr. Chessin considers the motion of a physical pendulum on the surface of the earth, taking into account the rotation of the earih about its axis. The inital velocity relatively to the earth of the pendulum is supposed equal to zero, as in Fuccanl's experimert. Hence he retains the name of "Foucault's pendulum," although oscillations of any finite amplitude are considered. The p rtrait which is given with this nuıber is that of M. E. Picard.

Wiedemann's Annalen der Physik und Chemie, No. 2.Fluorescence of solutions, by $\mathrm{O}$. Knoblauch. There is a constant rati, between the in ensity of the flurrescence and the existing light, $t$ ven $u$ hen the intensity of the latter is altered in the $\mathrm{ra}$ io of $\mathrm{I}$ to 6400 . The author proves exp rimentally and therreticaliy that the effect upon the various fluorescent bodies of virying the solvent is very different. - The potential gradient in the positive portion of the glow discharge, hy $\mathrm{A}$. Herz. The poienial gradient in the pusitive unstratifi d glow dis. charge of a vacuum tube decreases as the curren! increases, and also as the diameter of the tube is increased; but it increases with the prts-ure, thrugh not as rapidly.-Unipular induction, by Ernst Lecher. The author discusses the different aspects of the question whether, when a cylindrical magnet rotates $a b$ ut its axis, the lines of force due to it are siationary, or rntale wi $h$ the magnet. The former was Faraday's original view, the laiter has been maintained hy Tolver Preston and others. After showing that all the experiments hitherto quoted as der isive one $u$ ay or the other may be equally $u$ ell interpreted on either assump ion, he describes s'me test experimen's which show that he lines of force stand still wh le the magnet rotates:Electric dispersion, hy P. Drude. A $\mathrm{m}$-thot is described for inves igating the relation betwe en the di lect ic constant of a substance and the period of the ele c ric $n$ aves traversing it, or what may $b+$ described as the electric disperion of the substance. If the dielectric constant decreares as the period increase, there will be normal, if it incr ases, anomalous dispersion. Fer alcohol the dispersion was found to be normal, and of the sime order of magnitude as its eptical dispersion. Water sho sed abnormal dis er.ion with he la'ge wave-lengths use I, whereas e onite showed no pe ceptible dispersion.Eflect o kathode rays upon some salt;, by E. Goldstein. Lithium chlor'de, when exposed to Kathode rays, assumes a h. liotrope or dark violet colour, which it retain- for some time in a se.led tuhe. ( hl rrides and $\mathrm{o}$ her haloid silts of potassium and -orium show simiar efiects. The colours are very superficial, and disappear on heating, or by the action of moisture.

\section{SOCIETIES AND ACADEMIES. LONDON}

Geological Society, January 23.-Dr. Henry Woodward, F.R.S., President, in the chair. -Carrock Fell : a study in the variation of igneous rock-masses. Part ii. The Carrock Fell Granophyre. Part iii. The Grainsglll Greisen, by Alfred Harker. The augite-granophyre of Carrock Fell was first deccribed in its normal development, suecial attention being drawn to the various Iypes of nicrographic intergrowths which it exhibits. The vaitiation of the rock was next examined, 